\title{
El pensamiento resiliente y la planificación urbana en un entorno costero bajo riesgo de tsunami: el caso de Mehuín, Chile ${ }^{1}$
}

\author{
Paula Villagra ${ }^{2}$, Geraldine Herrmann ${ }^{3}$, Carolina Quintana ${ }^{4}$ y Roger D. \\ Sepúlveda ${ }^{5}$
}

\begin{abstract}
RESUMEN
La comprensión de cómo acomodar el "pensamiento resiliente" en la planificación de ciudades es fundamental para la adaptación de los entornos urbanos a eventos naturales extremos. Este estudio explora si el pensamiento resiliente se ha abordado en la planificación urbana, tanto desde la perspectiva conceptual como de la aplicada, utilizando Mehuín, Chile, como caso de estudio. La metodología se basa en: Una revisión cualitativa de las herramientas de planificación para analizar en qué medida los atributos de la resiliencia urbana (por ejemplo, la diversidad y la redundancia) se abordan en los documentos de planificación; y una evaluación cuantitativa de las dimensiones de la resiliencia del medio ambiente urbano de Mehuín (es decir, la física, ambiental y social). Los resultados muestran que la dimensión ambiental es la que más influye en la capacidad de adaptación de Mehuín; sin embargo, esta dimensión no se aborda en las herramientas de planificación urbana. Estos resultados divergentes se discuten adicionalmente con respecto a los posibles retos que se plantean en la ciencia de la planificación actual tal como la conocemos.
\end{abstract}

Palabras clave: Pensamiento resiliente, planificación urbana, tsunami

\begin{abstract}
It is critical to understand how to accommodate the 'resilience thinking' approach in city planning, in order for urban environments to adapt to extreme natural events. This study explored from both a conceptual and applied perspective, whether or not the resilience thinking approach has been adressed in urban planning, using Mehuin, Chile, as a case study. The methodology involved a qualitative review of planning tools, in orden to analyze the extent to which urban resilience attributes (e.g. diversity and redundancy) are addressed in Mehuin's planning, documents, along with a quantitative evaluation of resilience dimensions (i.e. physi-
\end{abstract}

1 Agradecemos a CONICYT Proyecto Fondecyt $\mathrm{N}$ 。 1150137 por la financiación de este estudio y a la Sra. Mina Fallahzadegan por su colaboración en la recolección y análisis de datos. Artículo recibido el 7 de marzo de 2016, aceptado el 12 de mayo de 2016 y corregido el 13 de junio de 2016

2 Instituto de Ciencias Ambientales y Evolutivas / Laboratorio de Paisaje y Resiliencia Urbana, Universidad Austral de Chile (Chile).

E-mail: paula.villagra@uach.cl
3 Escuela de Arquitectura, Universidad Diego Portales (Chile). E-mail: geraldine.herrmann@udp.cl

4 Laboratorio de Paisaje y Resiliencia Urbana, Universidad Austral de Chile (Chile).

E-mail: carolina.quintana@alumnos.uach.cl

5 Instituto de Ciencias Ambientales y Evolutivas, Universidad Austral de Chile (Chile). E-mail: rogersepulveda@uach.cl 


\begin{abstract}
cal, environmental and social) for Mehuin's urban environment. Our findings indicated that the environmental dimension has the greatest influence on the adaptive capacity of Mehuín; however, this is not addressed in the urban planning tools. These divergent results are further discussed with respect to the potential challenges that could arise in current planning science, as we know it.
\end{abstract}

Key words: Resilience thinking, urban planning, tsunami

El concepto de resiliencia -o la capacidad de un sistema para absorber las perturbaciones y reorganizarse después de un proceso de cambio con el fin de mantener la misma función, estructura, identidad y capacidad de retroalimentación (Walker et al., 2004)- se ha incluido en la planificación urbana con el objetivo de hacer frente a los retos que afrontan las ciudades en caso de desastres naturales. El 'pensamiento resiliente', introducido desde la ecología en el medio ambiente humano por Walker y Salt en el año 2006, se ha convertido en el marco 'de facto' para mejorar la preparación, respuesta y recuperación después de un desastre a nivel comunitario (Cutter et al., 2014). Sin embargo, la comprensión errónea del concepto en el ámbito de la planificación urbana desencamina comúnmente la elaboración y aplicación de estrategias para asegurar la resiliencia de las comunidades. Este es un reto, considerando que el concepto de resiliencia urbana suele ser erróneamente 'traducido' en las políticas de planificación. La comprensión de la resiliencia urbana a veces falla durante su conceptualización y/o implementación.

El pensamiento resiliente descrito por Walker y Salt (2006) ha influenciado la línea de investigación de varios científicos relacionados con la planificación. Ellos concuerdan que la planificación urbana debe incluir los siete atributos de la resiliencia con el fin de regular las comunidades humanas (Norris et al., 2008; Allan \& Bryant, 2011; Ahern, 2011). Estos son: Diversidad, o tener diferentes opciones para adaptarse a una amplia gama de circunstancias; redundancia, o tener múltiples elementos/componentes que proporcionan funciones similares en el caso de que otros fallen; multifuncionalidad, para apoyar la diversidad de respuestas requeridas después de un desastre; modularidad, para permitir que módulos individuales puedan seguir funcionando en caso que otros fallen; la red y la conectividad multiescala, o la cons- trucción de redes elásticas a través de circuitos redundantes; cruces de gobernanza, que se refiere a la redundancia en las estructuras de gobierno; y capacidad de adaptación con innovación, para fomentar el aprendizaje y la experimentación en el desarrollo de normas a nivel local.

Además, dentro del contexto de la planificación urbana se deben abordar tres dimensiones de la resiliencia; las dimensiones físicas, ambientales y sociales. La dimensión física se refiere a las características de la morfología urbana que afectan a la capacidad de adaptación de las ciudades, como la densidad de población, la cantidad de espacio abierto, la infraestructura construida útil para el refugio, y la distancia y la cantidad de rutas de evacuación, entre otros. La dimensión ambiental se refiere a las características de los sistemas naturales que proporcionan ventajas para la supervivencia después de un desastre como para la provisión, la mitigación y la regulación. Por último, la dimensión social se refiere a las características de las comunidades que influyen en la resiliencia, incluyendo porcentaje de pobreza, población con necesidades especiales, la participación en organismos de emergencia y número de organizaciones civiles y de emergencia.

El enfoque del pensamiento resiliente sugiere incluir los siete atributos de la resiliencia en los instrumentos de planificación para obtener una planificación más adaptable a cambios inesperados. Estos atributos pueden ser considerados en uno o más de un instrumento, pero el conjunto de documentos que componen los instrumentos de planificación de una comunidad deben incluirlos en la mayor medida posible. Del mismo modo, las tres dimensiones de la resiliencia deben abordarse en la planificación urbana con el fin de mejorar la capacidad de recuperación de la comunidad. 
En Chile, el concepto de resiliencia se introdujo en el ámbito de la planificación urbana después del terremoto y tsunami de 2010 (Mw8.8) que destruyó una amplia zona del territorio costero. Sin embargo, y hasta hoy, no es claro si las actuales estrategias de planificación urbana están en línea con el enfoque del pensamiento resiliente, que anima a planificar con una perspectiva multidimensional, considerando la capacidad de recuperación del territorio. Este estudio tiene como objetivo explorar esta temática preguntando: ¿En que medida están las herramientas de planificación urbana abordando la resiliencia de las comunidades costeras? Esta investigación utiliza la localidad de Mehuín como caso de estudio en el sur de Chile. De acuerdo con ello, los objetivos son los siguientes: En primer lugar, explorar si los atributos de la resiliencia son abordados por las herramientas que regulan la planificación de Mehuín; y en segundo lugar, evaluar las dimensiones de la resiliencia del medio ambiente urbano de Mehuín en caso de tsunami. La Figura $\mathrm{N}^{\circ} 1$ ilustra el modelo de estudio.

\section{Metodología}

Mehuín es una localidad costera en el sur de Chile (comuna de Mariquina, Región de Los Ríos). Tiene una población aproximada de 1.135 habitantes (INE, 2005) y se encuentra en la desembocadura del río Lingue en una estrecha Ilanura costera, junto a las montañas de la costa (cordillera de la Costa) que alcanzan hasta 200 metros en esa zona. Las principales actividades económicas de sus habitantes son la pesca y el turismo, recibiendo una gran cantidad de visitantes durante el verano. Mehuín puede ser claramente dividida en cinco áreas de estudio con carácter distintivo por su forma urbana y geografía, que pueden afectar la capacidad de recuperación postsunami. Estas son: Mehuín Bajo (área rural indígena), Mehuín Caleta (área urbana a lo largo del río para la residencia permanente), Mehuín Balneario (área urbana mixta de residencia permanente y temporal, a lo largo de la playa), Pichicuyín (área rural mixta de residencia permanente y temporal en una pendiente pronunciada frente al mar) y Mississippi (área residencial urbana en una pendiente pronunciada frente al mar) (Figura $N^{\circ} 2$ ).
Dado que nuestro estudio incluye la exploración de datos nominales (que se encuentran en los documentos de planificación) y ordinales (para medir las variables de la resiliencia), la metodología incluye un enfoque cualitativo y cuantitativo mixto.

El enfoque cualitativo fue adaptado de la 'grounded theory' y el análisis de contenido para explorar si las herramientas de planificación de Mehuín están abordando los atributos de la resiliencia. Textos y mapas comprenden las fuentes de estudio. Estos incluyen el Mapa de Protección Civil contra Tsunamis (ONEMI, 2013), el Plan de acción en Caso de Tsunami y Terremoto (Municipio de Mariquina, no publicado), el Plan Regional de Emergencia (ONEMI, 2012) y el Plan Regulador Comunal (Municipalidad de Mariquina, 2015). Cada uno de estos documentos de planificación se analizó y codificó en los siete atributos de la resiliencia descritos en la introducción. Estos son: diversidad, redundancia, multifuncionalidad, modularidad, red y conectividad multiescala, cruces de gobernanza y capacidad de adaptación con innovación. El proceso de codificación fue realizado por dos investigadores con conocimiento en el pensamiento resiliente en el entorno urbano. La frecuencia de mención de cada atributo muestra si las herramientas de planificación se enfocan en la resiliencia o no. El Cuadro $N^{\circ} 1$ muestra ejemplos de los aspectos de la resiliencia encontrados en cada herramienta de planificación. En consecuencia, la frecuencia total informará sobre el nivel de contribución de cada herramienta de planificación urbana a la resiliencia, en comparación con las demás, tanto en forma positiva o negativa.

El enfoque cuantitativo se utilizó para medir las variables de la resiliencia en el medio urbano de Mehuín y explorar en qué medida cada dimensión contribuye a esta. Para este propósito, se midieron las variables asociadas con las dimensiones física, social y ambiental (descritas en la introducción) en cada área de estudio (ver Figura $N^{\circ} 2$ ), utilizando las bases de datos de la Municipalidad de Mariquina, Corporación Nacional Forestal (CONAF) y la Oficina Nacional de Emergencia (ONEMI). Las unidades geomorfológicas y de uso de suelo se determinaron sobre la base de la cobertura proporcionada por CONAF (2006), la cual se corrigió y complementó con informa- 
ción proveniente de Google Earth y de la recopilada durante las visitas de campo. Esto se realizó utilizando el software ArcGIS 10.3.1 y la herramienta de medida, con la cual se calcularon las distancias euclidianas entre la comunidad y los recursos de provisión, rutas de evacuación, y las superficies de los espacios abiertos y construidos. Las mediciones de las variables vinculadas a la dimensión social se calcularon utilizando las bases de datos locales y nacionales de acceso gratuito, como las del Instituto Nacional de Estadísticas (INE), de la Encuesta de Caracterización Socioeconómica Nacional (CASEN), y de la Municipalidad de Mariquina. Para analizar la relación entre los datos recopilados se llevó a cabo el Análisis de Componentes Principales (PCA) utilizando veintiún indicadores que abordan los aspectos físicos, ambientales y sociales de la resiliencia. De esta manera se obtuvieron relaciones entre los indicadores y las cinco áreas de estudio. Las variables que no mostraron variación entre las áreas de estudio (es decir, las variables con datos a nivel comunal, tales como la participación social, los simulacros de tsunami, la pobreza de la población, y la población con necesidades especiales) no se incluyeron en los análisis de PCA. Los resultados se ilustran en modelos biplot utilizando los dos primeros componentes principales para cada dimensión, los cuales explican más de $80 \%$ de la varianza total.

\section{Contribución de las herramientas de planificación a la resiliencia de Mehuín}

El análisis de las herramientas de planificación indica que estas si consideran aspectos de la resiliencia, aunque el concepto en sí no se menciona directamente. Teniendo en cuenta todas las herramientas, se hizo referencia a los atributos de la resiliencia 48 veces. De esta cantidad, el $72,9 \%$ son aspectos que contribuyen positivamente a la resiliencia, y el 27,1\% contribuyen de una manera negativa.

En relación a los aspectos positivos, la Figura $N^{\circ} 3$ muestra que la mayoría de las herramientas de planificación abordan cuestiones relacionadas con la diversidad (22\%), redundancia (29\%) y multifuncionalidad (26\%). El Plan Regional de Emergencia es el más completo de todos, porque se refiere a todos los atributos con énfasis en la red y conectividad multiescala $(25 \%)$ y los cruces de gobernanza (25\%). Por el contrario, El Mapa de Protección Civil contra Tsunami solo se refiere a los atributos de redundancia y multifuncionalidad, lo cual era de esperar ya que esta herramienta solo se compone de un mapa que indica el número y ubicación de las rutas de evacuación y zonas de seguridad. Además, es interesante darse cuenta de que el Plan Regulador Comunal, a pesar de que es el único documento que no se refiere a las emergencias en particular, incluye medidas que aumentan la resiliencia. En concreto, esta herramienta promueve el desarrollo de diversas áreas verdes, de diferentes tamaños y tipos, lo cual contribuye a la multifuncionalidad de la ciudad después de un desastre, proporcionando espacios abiertos en los cuales refugiarse, localizar recursos y otras necesidades que surgen después de una catástrofe.

\section{Modelos biplots de resiliencia}

El PCA de síntesis (Figura N5a) indica que las dimensiones física y ambiental contribuyen mayormente a la resiliencia de Mehuín. Sin embargo, el análisis eigenvector muestra que las variables ambientales son las más importantes para diferenciar entre las áreas de estudio dentro de Mehuín (véase la Cuadro $\mathrm{N}^{\circ} 3$ ). Las variables sociales, por otro lado, están cerca del origen del PCA; por lo tanto, afectan en menor medida a la resiliencia. Las Figuras $\mathrm{N}^{\circ} 5 b, \mathrm{~N}^{\circ} 5 \mathrm{c}$ y $\mathrm{N}^{\circ} 5 \mathrm{~d}$ proporcionan información más detallada para entender las diferencias entre la capacidad de resiliencia de las áreas de estudio.

Con respecto a los resultados de las variables ambientales para cada área de estudio, la Figura $N^{\circ} 5 \mathrm{c}$ muestra que existen diferencias entre todas las áreas. Solo Pichicuyín y Mississippi se agrupan en el biplot. La ubicación opuesta de las variables de buffer de inundación natural (NFB) y buffer de bosque (FB) en el PCA, indica la limitada capacidad de los humedales y bosques para mitigar los efectos de un tsunami en Pichicuyín y Mississippi. En estos casos en particular, esto es debido a la falta de humedales costeros y bosques entre estas áreas de estudio y el mar (Figura $N^{\circ} 2$ ). Mehuín Bajo, 
por el contrario, está cerca en el biplot de las variables de provisión de agua (WPD), de alimentos (FPD) y de leña (FWPD). Esto indica que la distancia a estos recursos, una vez en una zona segura, es mayor de lo que se mide en las otras áreas de estudio, lo cual reduce su capacidad de adaptación tras el tsunami. Por otro lado, el sistema de humedales que rodea Mehuín Caleta, así como el sistema de dunas semiestabilizadas entre Mehuín Caleta y el mar, contribuye a la capacidad de adaptación postsunami de esta área. Por último, la zona de Mehuín Balneario, se ve favorecida por las variables de buffer de dunas (NDBh, NDBC) que comprende las mismas dunas asociadas a Mehuín Caleta, y que se extienden hacia el norte. Sin embargo, esta zona también se asocia con la variable tipo de suelo (ST) que indica que la playa de arena entre esta zona y el mar, no contribuye a la resiliencia.

\section{Herramientas de planificación y resiliencia urbana}

El principal hallazgo de esta investigación es la divergencia de resultados que se encuentran entre el estudio de las herramientas de planificación asociados a Mehuín, y el estudio del entorno urbano de Mehuín. En el segundo caso, este estudio revela que la dimensión ambiental es la que contribuye mayormente a la resiliencia comunitaria, seguida de la dimensión física, y la dimensión social. Sin embargo, la revisión detallada de los documentos de planificación de Mehuín muestra que la dimensión ambiental apenas está siendo considerada en la planificación urbana. De hecho, ninguno de los documentos de planificación menciona el importante papel que los ecosistemas costeros y áreas de inundación natural desempeñan en la mitigación de los efectos de tsunami y en la provisión de los recursos básicos para la supervivencia después de un desastre. De hecho, los buffer de inundación natural como los humedales, dunas y bosques, no están protegidos por ningún instrumento de planificación legal a nivel regional o local. Cabe señalar que el aumento de la resiliencia de las comunidades pobres a través de la 'infraestructura natural' es una oportunidad no solo para mejorar la reducción del riesgo de desastres, sino también para proporcionar beneficios adicionales, tales como los servicios ambientales y recreativos (Millennium Ecosystem Assessment, 2005). Este problema también es reconocido por los diferentes modelos de resiliencia comunitaria (Norris et al., 2008; Renschler et al., 2010) los cuales indican considerar aspectos de los recursos naturales para evaluar la capacidad de recuperación en caso de desastres.

Los planificadores urbanos deben tener esto en cuenta en el caso de Mehuín, así como para toda la costa chilena que se caracteriza por una rica cantidad y diversidad de recursos naturales, muchos de los cuales no están contemplados en la planificación urbana. Esto es particularmente un problema en el caso del Plan Regulador Comunal, que tiene un ámbito de acción que está restringido por el límite urbano, y por ende, sin inherencia en la regulación de los recursos naturales fuera del área urbana. Estos recursos, como se encontró en Mehuín, pueden incluir los servicios de amortiguación y provisión necesarios para la mejora de la capacidad de resiliencia en caso de tsunami. Sin embargo, cabe destacar que lamentablemente en Chile no existen instrumentos de planificación vinculantes para regular los terrenos ubicados fuera de las zonas urbanas. Esto es especialmente problemático para mejorar la resiliencia costera, ya que muchos de los recursos naturales relevantes -por ejemplo, buffers de inundación como los humedales o los bosques- a menudo se encuentran adyacentes a los asentamientos costeros, pero fuera de los límites urbanos. Como consecuencia de ello, en Chile las zonas de inundación causadas por tsunamis fuera de las zonas urbanas no pueden ser reguladas de manera vinculante.

Además, la gestión integrada de recursos naturales y la planificación del uso del suelo no es solo una labor para un planificador, sino también para un ecólogo. El papel de los servicios ecosistémicos después de un desastre está determinado también por los cambios que ocurren en el mismo ecosistema. Por lo tanto, evaluaciones a nivel de paisaje también deben llevarse a cabo para identificar los mecanismos por los cuales funcionan los ecosistemas costeros, y cómo pueden ser alterados por las perturbaciones. Dado que los ecosistemas son dinámicos, su efecto sobre la capacidad de recuperación de la comunidad 
puede variar significativamente a través del tiempo (Ingram \& Khazai, 2012).

\section{Conclusión}

El estudio de los instrumentos de planificación urbana y del entorno urbano de Mehuín indica que la dimensión más importante en la construcción de la resiliencia comunitaria en el caso de Mehuín, es la dimensión ambiental. Especialmente, los buffers de inundación natural y los recursos naturales son relevantes para el suministro de alimentos, agua y fuego después de un desastre. Estos necesitan ser reconocidos y protegidos con urgencia, a través de documentos de planificación urbana vinculantes a escala regional y local, que lamentablemente en la actualidad se centran en gran medida en la dimensión física de la resiliencia. Las herramientas de planificación vinculantes estipulan las reglas para todos los actores, y garantizan con ello el cumplimiento de las normas por todas las partes implicadas, que a menudo tienen intereses en conflicto. Como se ha indicado, los instrumentos de planificación vinculantes para definir el uso del suelo y zonas de riesgo solo existen en Chile para las zonas urbanas. Sin embargo, para las zonas rurales fuera de las áreas urbanas, instrumentos de planificación vinculantes para regular el uso del suelo no están disponibles. Esto presenta una gran debilidad para aumentar la resiliencia de las comunidades, ya que las zonas de riesgo, zonas sin construcciones, áreas buffer y el uso del suelo en general, necesitan ser designados de manera vinculante para garantizar el cumplimiento de las normas por todos los actores.

Abordar el reto de la resiliencia en la planificación requiere claramente un enfoque multidisciplinario e integrador que se diferencia de la planificación actual tal como la conocemos, con un enfoque en los sistemas físicos mayormente. Además, el pensamiento resiliente sugiere que la resiliencia se debe abordar como un proceso, no como un resultado, lo cual podría ser lo más difícil de lograr. Aunque este estudio mostró que se abordan aspectos de la resiliencia, estos están formulados para cumplir objetivos específicos en un marco de tiempo determinado, sin tener en cuenta que la resiliencia de la población está en constante evolución y no tiene un final. Es más, cuando se trata de planificar para hacer frente a los desastres, las herramientas de planificación no han sido capaces de anticiparlos, actuando de manera reactiva, tratando de reconstruir lo que fue destruido. Esto no es suficiente, ya que los cambios que pueden afectar a Mehuín debido a perturbaciones naturales, no son ni cien por ciento predecible ni planeados. Por lo tanto, los atributos de la resiliencia encontrados en este estudio no son decisivos para contribuir a la capacidad de adaptación postdesastre. Sí, son indicadores de la situación actual apuntando a las áreas que falta abordar. Por lo tanto, para introducir el pensamiento resiliente en la planificación, se requiere un marco más flexible de herramientas de planificación, que se pueda adaptar a cambios inesperados, centrándose más en el proceso de construcción de la resiliencia comunitaria, que en los resultados.

Con el pensamiento resiliente en mente, planificadores de territorios costeros pueden considerar el papel de los recursos naturales en la resiliencia de la comunidad después de un desastre, y así, planificar el territorio costero como un sistema dinámico. De hecho, cuando los planificadores discutan la ciencia emergente de la resiliencia en el contexto de la planificación y el concepto de servicios ecosistémicos en la planificación urbana de adaptación, deben integrar las dimensiones ambiental, física y social de la resiliencia con el fin de afrontar cambios, perturbaciones e incertidumbres, en aras de mejorar la adaptabilidad.

\section{Referencias bibliográficas}

AHERN, J. From fail-safe to safe-to-fail: Sustainability and resilience in the new urban world. Landscape and Urban Planning, 2011, No 100, p. 341-343.

ALLAN, P. \& BRYANT, M. Resilience as a framework for urbanism and recovery. Journal of Landscape Architecture, 2011, p. 34-45.

CUTTER, S.L.; ASH, K.D. \& EMRICH, C.T. The geographies of community disaster resilience. Global Environmental Change, 2014, $N^{\circ} 29$, p. 65-77. 
INGRAM, J.C. \& KHAZAI, B. Incorporating Ecology and Natural Resource Management into Coastal Disaster Risk Reduction. In: INGRAM, J.C.; DECLERCK, F. \& RIO, C.R.D. (editors). Integrating ecology and poverty reduction. New York: Springer, 2012, p. 369392.

NORRIS, F.; STEVENS, S.; PFEFFERBAUM, B.; WYCHE, K. \& PFEFFERBAUM, R. Community resilience as a metaphor, theory, set of capacities and strategy for disaster readiness. Community Psychology, 2008, № 41, p. 127 150.

RENSCHLER, C.S.; FRAIZE, A.E.; ARENDT, L.A.; CIMELLARO, G.P.; REINHORN, A. \&
BRUNEAU, M. A Framework for Defining and Measuring Resilience at the Community Scale: The PEOPLES Resilience Framework. New York. 2010.

WALKER, B.; HOLLING, C.S.; CARPENTER, S.R. \& KINZIG, A. Resilience, adaptability and transformability in social-ecological systems. Ecology and Society, 2004, Vol. 9, $N^{\circ} 2$, p. 5.

WALKER, B. \& SALT, D. Resilience thinking: sustaining ecosystems and people in a changing world. Washington: Island Press, 2006. 
